\title{
The Effect of Urbanization and Economic Performance on Metropolitan Water Consumption: Theoretic Model and Evidence from Guangzhou of China
}

\author{
Shaohui $\mathrm{Gao}^{1,2}$, Yiming $\mathrm{He}^{3,4}$ \\ ${ }^{1}$ College of Economics \& Management, South China Agricultural University, Guangzhou, Guangdong 510642, China \\ ${ }^{2}$ College of Business Administration, University of Texas at El Paso, El Paso, TX 79968-0543, USA \\ ${ }^{3}$ Division of Resource Management, P.O. Box 6108, West Virginia University, Morgantown, WV 26506, USA \\ ${ }^{4}$ School of National Agricultural Institution and Development, South China Agricultural University, Guangzhou, \\ Guangdong 510642, China
}

Correspondence: Yiming He, Division of Resource Management, P.O. Box 6108,West Virginia University, Morgantown, WV 26506, USA \& School of National Agricultural Institution and Development, South China Agricultural University, Guangzhou, Guangdong 510642, China.

Received: December 14, 2016

doi:10.11114/aef.v4i2.2076
Accepted: December 30, 2016 Available online: February 8, 2017

URL: http://dx.doi.org/10.11114/aef.v4i2.2076

\begin{abstract}
This paper examines the effect of urbanization and economic performance on metropolitan water consumption in Guangzhou of China. We develop social and individual optimal models to reveal the impact of urbanization and economic performance on metropolitan water consumption. Based on aggregated annual data from 1949 to 2014, the empirical results from OLS and ARDL suggest that previous water consumption per capita, urbanization and GDP per capita each play vital roles impacting metropolitan water consumption per capita in Guangzhou.
\end{abstract}

Keywords water consumption, urbanization, metropolitan performance, ARDL, Guangzhou

JEL classification Q25, O11, C32

\section{Introduction}

There are many studies on nexus between water and urbanization(Haase, 2009; Gober,2010; Wu et al.,2012; Barron and Donn,2013; Srinivasan et al.,2013; Yan et al., 2015; Engel et al.,2015; Maheshwari and Bristow,2016 ), but not many which examine the nexus among water consumption, urbanization, and economic growth. So, the objective of the paper is to examine the relationship among these variables. In this paper, we focus on the impact of urbanization and economic performance on water consumption, in Guangzhou of China from 1949 to 2014, applying OLS and ARDL these two econometric approaches.

Meanwhile, in terms of the research on the nexus between water consumption and urbanization, relatively little published literature examine this relationship (Katz, 2015). Gleick (2003) discusses definitions of water use, explores the history of water use around the world and in characteristic regions, identifies problems with collecting and analyzing water data, and addresses the question of improving water-use efficiency and productivity in different regions and economic sectors. He even found no discernable relationship between per capita national water withdrawals and income.

Barbier (2004) builds a growth model that includes this congestible nonexcludable good as a productive input for private producers. Growth is negatively affected by the government's appropriation of output to supply water but positively influenced by the contribution of increased water use to capital productivity, leading to an inverted-U relationship between economic growth and the rate of water utilisation. Cross-country estimations confirm this relationship and suggest that for most economies current rates of fresh water utilisation are not yet constraining growth. However, for a handful of countries, moderate or extreme water scarcity may adversely affect economic growth. Nevertheless, even for water-scarce countries, there appears to be little evidence that there are severe diminishing 
returns to allocating more output to provide water, thus resulting in falling income per capita. These results suggest caution over the claims of some hydrological-based studies of a widespread global 'water crisis.

Cazcarro, et al., (2013) examine how technology, processes of input substitution, and changes in final demand, all of which underlie economic growth, influence water consumption. Their analysis is undertaken for Spain during a significant socio-economic period, from 1980, the beginning of the democratic era, to 2007, the onset of the current economic crisis. To this end, they construct water consumption series linked to a time series of input-output tables generated for the Spanish economy, and they develop a structural decomposition analysis to study mainly changes in water consumption embodied in final demand. They find that the growth in Spanish demand would have implied an increase in water consumption almost three times the growth actually observed. However, this demand effect is largely offset by technology and intensity effects, mainly due to changes in agricultural crops. Given the importance of the demand growth, the final demand effect is also analyzed in detail, broken down by categories as well as level and composition. Household demand and the increase of exports appear as key explicative factors.

Ngoran et al.,(2016) suggest that economic growth in Sub-Saharan African countries is driven mainly by water and labor. Capital and energy were found not to significantly drive economic growth.

Obviously, previous empirical studies above have come under scrutiny in distinct literatures, the literatures remain disjointed. On one hand, the literature on the nexus between water consumption and economic growth does not consider the effect of urbanization. On the other hand, the studies on water consumption and urbanization just refer to their relationship but not the direct influence from economic performance. Although some empirical researches have calculated the empirically the links between water consumption and GDP, and the nexus between water consumption and urbanization, they do not examine the logic linkage among urbanization, economic performance and water consumption with theoretic models and in the same regression function. So, this study begins by explicitly linking the two literatures while providing insights into the interaction relationship among urbanization, economic performance and water consumption and investigates the interaction relationship among those three variables.

The rest of the paper is organized as follows. Section two presents a social and individual optimization model of water consumption in the presence of equipment complimentary and concerning water equipment capacity in the metropolitan economic growth. Section three describes the data used to carry out the econometric analysis and then summarizes empirical results. Section four provides the conclusions.

\section{Theoretic Model}

Consider the optimization problem of an individual who cares about the water resource that consumed indirectly through water access equipment, such as water tube and tap, and who takes into account the complimentary effect of water equipment on the water consumption. On the other hand, water is most used by industries, so when the total production output increase, as one kind of input, water also increase with a stable marginal speed respect to total income. In terms of the equipment for water use, individuals just need the tap and hose that are public goods supplied by government.

\section{(1) Social Optimal Model}

The social optimal model that we apply is originally introduced by Carroll et.al, (2000). But comparing with Carroll et.al,(2000)'s model that focus on saving behavior with habit, our model that just concentrates on water consumption with equipment is

$$
\begin{aligned}
\max _{w c, E} \int_{0}^{\infty} U(w c, E) e^{-\theta t} d t=\max _{w c, E} \int_{0}^{\infty} \frac{\left(\frac{w c}{E V}\right)^{1-\sigma}}{1-\sigma} e^{-\theta t} d t \\
\text { s.t. }\left\{\begin{array}{l}
\frac{d E}{d t}=\rho(w c-E) \\
\frac{d k}{d t}=(A-\delta) k-w c
\end{array}\right.
\end{aligned}
$$

Where $\mathrm{U}($.$) represents the individual's utility function, \mathrm{E}$ is the equipment to water use, wc is the water consumption, $\sigma$ is the coefficient of relative risk aversion, and $\gamma$ indexes the importance of equipment and we assume $\sigma>1$ and $0 \leq \gamma<1$. Equation (2) represents the equipment complimentary degree to water consumption, with the parameter $\rho(\geq 0)$ determining the relative weights of equipment complimentary to water consumption at different times.

We assume the metropolitan economic growth function with the urbanization A and water equipment capacity $\mathrm{K}$ is $Y=A K$. So, according to Carroll et.al,(2000)'s model, we get the water capacity evolves like equation (3), where water vaporization and leak because of the water equipment expired depreciates at rate $\delta \geq 0$. 
The Hamiltonian function (Chiang and Wainwright,2004) is

$$
H=U(w c, E)+\varphi[(A-\delta) k-w c]+\mu \rho(w c-E)
$$

Carroll et.al,(2000) present the full solution to this problem with equations of motion relating consumption.

$$
\begin{gathered}
\frac{d}{d t}\left(\frac{\frac{d w c}{d t}}{w c}\right)=\sigma\left(\frac{\frac{d w c}{d t}}{w c}\right)^{2}+\frac{\frac{d w c}{d t}}{w c}[2 \theta+\rho+\delta-A-2 \gamma \rho(1-\sigma)]-\rho^{2} \gamma[\gamma(1-\sigma)+1]\left(\frac{w c}{E}\right)^{2} \\
+2 \gamma \rho(1-\sigma) \frac{d w c w c}{d t \quad E}+\left(\frac{\rho \gamma}{\sigma}\right) \frac{w c}{E}[\rho \gamma(1-\sigma)(2 \sigma-1)+\theta+\rho-\sigma(2 \theta+\delta-A)]+\frac{1}{\sigma}\{(\rho+\theta)(\theta+\delta-A)+\rho \gamma(1-\sigma)[\rho(\gamma(1- \\
\sigma)+1)-(2 \theta+2 \rho+\delta-\mathrm{A})]\}=0
\end{gathered}
$$

Setting the dynamic equation above equal to zero determines the steady state of the model,

$$
\frac{\frac{d w c}{d t}}{w c}=\frac{A-\delta-\theta}{\gamma(1-\sigma)+\sigma}
$$

In the steady state, water consumption (wc) and metropolitan economic growth (g) both grow at the same rate.

$$
g=\frac{d Y}{Y}=\frac{\frac{d w c}{d t}}{w c}
$$

So, $g=\frac{A-\delta-\theta}{\gamma(1-\sigma)+\sigma}$ and then $\frac{d g}{d A}=\frac{1}{\gamma(1-\sigma)+\sigma}$.

Here, we assume metropolitan aggregate demand function is $Y=(E+w c)+\varepsilon$. Where $\varepsilon$ represents other types of aggregate demand in metropolitan level such as investment, government expenditure and net export. With an AK production function with depreciation rate $\delta$, water consumption must be enough to make the water capacity grow at rate $\mathrm{g}$ after depreciation:

$$
E=Y-w c-\varepsilon=(g+\delta) \mathrm{K}=\frac{(g+\delta) \mathrm{Y}}{A} .
$$

Differentiating this expression with respect to g yields

$$
\frac{\mathrm{dE}}{d g}=\frac{A Y-(g+\delta) \frac{d A}{d g} Y}{\beta A^{2}}=Y\left[\frac{A-(g+\delta) \frac{d A}{d g}}{\beta A^{2}}\right]=\mathrm{Y}\left[\frac{A-(g+\delta)[\gamma(1-\sigma)+\sigma]}{\beta A^{2}}\right] .
$$

As a result, if $A-(g+\delta)[\gamma(1-\sigma)+\sigma]>0$ or $\sigma<1+\frac{\theta}{\delta(1-\gamma)}$, and then $\frac{\mathrm{dE}}{d g}>0$.

Additionally, according to the definition of rate of economic growth $g(t)=\frac{\frac{d Y}{d t}(t)}{Y(t)}$, we get the derivative of $g$ with respect to $\mathrm{t}$,

$$
\frac{\mathrm{dg}}{d Y}=\frac{\frac{d}{d t}\left(\frac{\mathrm{dY}}{d t}\right) Y-\left(\frac{\mathrm{dY}}{d t}\right)^{2}}{Y^{2}}
$$

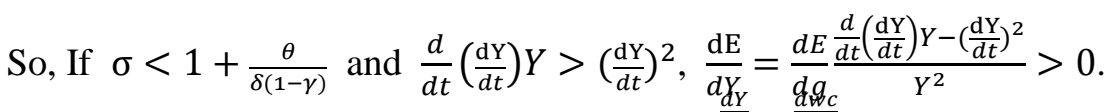

On the other hand, from the steady state condition $\frac{d t}{Y}=\frac{\frac{d d}{d t}}{w c}$, we take integration in both sides

$$
\int \frac{1}{Y} d Y=\int \frac{1}{w c} d w c+\mathrm{B}
$$

The solution of the equation above is $\operatorname{Ln} Y=\operatorname{Ln} w c+B$ or $\mathrm{Y}=e^{\operatorname{Lnw} c+B}$. Then by the equation $F(Y, w c)=\operatorname{Ln} Y-$ $L n w c-B=0$ and the implicit function theorem, we obtain the a corollary 
Corollary $1 \frac{d w c}{d Y}=-\frac{\frac{\partial F}{\partial Y}}{\frac{\partial F}{\partial w c}}=-\frac{\frac{1}{Y}}{-\frac{1}{w c}}=\frac{w c}{Y}=\frac{w c}{e^{\operatorname{Ln} w c+B}}>0$

From equation (3), in terms of the short run, we have $\frac{d k}{d t}=0=(A-\delta) k-w c$. That's to say, $w c=(A-\delta) k$. So, we obtain the second corollary:

Corollary $2 \frac{d w c}{d A}=k>0$.

(2) Individual's Optimal Model

The individual's optimal model that we continue to apply Carroll et.al, (2000) model, but comparing with Carroll et.al,(2000)'s model that focus on saving behavior with habit.

$$
\begin{aligned}
& \max _{c, h} U(c, h)=\max _{c, h} \frac{\left(\frac{c}{h)^{1}}\right)^{1-\sigma}}{1-\sigma} e^{-\theta t} d t \\
& \text { s.t. }\left\{\begin{array}{l}
\frac{d h}{d t}=\rho(c-h) \\
\frac{d k}{d t}=y-(o c+c)-(n+\delta) k
\end{array}\right.
\end{aligned}
$$

Where $\mathrm{U}($.$) represents the individual's utility function, \mathrm{h}$ is the stock of habits, $\mathrm{c}$ is the instantaneous flow of the sum of consumption of water and water equipment, oc represents other consumption except from c, $\sigma$ is the coefficient of relative risk aversion, and $\gamma$ indexes the importance of consumption habits and we assume $\sigma>1$ and $0 \leq \gamma<1$. Following Carroll et.al(2000), if $\gamma=0$ then only the absolute level sum of consumption matters and consumption habits does not matter. If $\gamma=1$, then consumption relative to the habit stock is all that matters. Note that, in Carroll's paper, habits and consumption can move in opposite directions (consumption goes up habits go down, or vise versa). Here, we assume $\mathrm{c}$ is an increasing functional of water consumption $(\mathrm{wc})$ and water equipment consumption(E): $\mathrm{c}=c(w c, E)$, $\frac{\partial c}{\partial w c}>0$, and $\frac{\partial c}{\partial E}>0$.

Equation (5) represents the habit stock is a weighted average of past sum of consumption with the parameter $\rho(\geq 0)$ determining the relative weights of sum of consumption at different times. The larger is $\rho$, the more important is the sum of consumption in recent past.

Furthermore, we assume the long run economic growth function with the urbanization A and per capita water $\mathrm{k}(=\mathrm{K} / \mathrm{L})$ is $y=A k L$. Here, $\mathrm{y}(=\mathrm{Y} / \mathrm{L})$ is per capita output, $\mathrm{K}$ represents total water supply and $\mathrm{L}$ represents total labor.

When we denote labor grows as $\frac{d L / d t}{L}=\mathrm{n}(\mathrm{n}>0)$, we can obtain the $\mathrm{dK} / \mathrm{dt}$ by differentiating $\mathrm{K}(\mathrm{t})=\mathrm{k}(\mathrm{t}) \mathrm{L}(\mathrm{t}): \frac{d K}{d t}=L \frac{d k}{d t}+$ $k \frac{d L}{d t}=L \frac{d k}{d t}+k n L$. On the other hand, when I represents investment and S represents saving, and the rate of water equipment depreciation is $\delta \geq 0$, according to the water stock identity $\mathrm{K}(\mathrm{t})=\mathrm{K}(\mathrm{t}-1)+\mathrm{I}-\delta \mathrm{K}$ and macroeconomic equilibrium for two sectors $(\mathrm{I}=\mathrm{S})$, we get $\frac{d K}{d t}=\frac{\mathrm{K}(\mathrm{t})-\mathrm{K}(\mathrm{t}-1)}{t-(t-1)}=\mathrm{S}-\delta \mathrm{K}$. So, $L \frac{d k}{d t}+k n L=\frac{d K}{d t}=\mathrm{S}-\delta \mathrm{K}$. And through saving function $\mathrm{S}=\mathrm{Y}-\mathrm{C}$, and then $L \frac{d k}{d t}+k n L=Y-C-\delta \mathrm{K}$, so $\frac{d k}{d t}=y-t c-(n+\delta) k=y-(o c+c)-(n+\delta) k$, where tc is per capita total different kinds of consumption.

The Lagrange function is

$$
\mathcal{L}=U(c, h)+\varphi[y-(o c+c)-(n+\delta) k]+\mu \rho(c-h)
$$

The resulting first-order conditions are 


$$
\begin{gathered}
\frac{\partial \mathcal{L}}{\partial c}=\left(\frac{c}{h^{\gamma}}\right)^{-\sigma} e^{-\theta t}-\varphi+\mu \rho=0 \\
\frac{\partial \mathcal{L}}{\partial h}=-\gamma h^{\gamma(\sigma-1)-1} c^{1-\sigma} e^{-\theta t}-\mu \rho=0 \\
\frac{\partial \mathcal{L}}{\partial \varphi}=y-(o c+c)-(n+\delta) k=0 \\
\frac{\partial \mathcal{L}}{\partial \mu}=\rho(c-h)=0
\end{gathered}
$$

So, the optimal solutions are

$$
\begin{gathered}
\varphi^{*}=e^{(n+\delta-\mathrm{AL}) t} \varepsilon, \quad \varepsilon \text { is a constance } \\
\mu^{*}=e^{\rho t} \epsilon, \quad \epsilon \text { is a constance } \\
c^{*}=h^{*}=y^{*}-o c-(n+\delta) k
\end{gathered}
$$

So, we get a corollary:

$$
\frac{d w c^{*}}{d y^{*}}=\frac{d w c^{*}}{d c^{*}} \frac{d c^{*}}{d y^{*}}=\frac{1}{\frac{d c^{*}}{d w c^{*}}} \times 1>0
$$

Corollary3 If $\mathrm{c}$ is an increasing functional of wc, $\frac{d w c^{*}}{d y^{*}}=\frac{d E C^{*}}{d Y^{*}}>0$.

The economic implication of corollary 3 is that in short run, only if $\mathrm{c}$ is an increasing functional of wc, on the equilibrium, output will improve water consumption.

In short, the economic explanation the relationship between the social optimal model and individual's optimal model is that the social optimal model aggregates the individuals' preference relation and replaces the individual's utility function with the social welfare function subject to dynamic conditions. Furthermore, individual's optimal model only considers the static conditions. As a result, social optimal model represents the long run status, while individual optimal model represents the short run status, which will be tested in the empirical section.

\section{Empirical Tests}

\subsection{Data Sources and Hypothesis}

The time series data about the water consumption, urbanization and economic performance of Guangzhou are from 1949 to 2014. The time series data about the GDP, water consumption, urbanization are obtained from the Guangzhou statistical yearbooks from 2000-2015 and the "Guangzhou 50 years"(GSD,2015).The direction of causality among urbanization, water consumption and metropolitan economic growth in the light of the literature overview is not consistent and depends on different datasets, the characteristics of different countries and the different econometric methodologies applied. Taking into account about the three corollaries in the section part, we may expect that the following hypothesis might hold true for Guangzhou:

Hypothesis 1 There exists positive effect from metropolitan economic performance on water consumption of Guangzhou.

Hypothesis 2 There is positive effect of urbanization on water consumption of Guangzhou.

\subsection{Variable Descriptions and Summary Statistics}

Table 1. Variable Definitions

\begin{tabular}{lllll}
\hline Variable & & Mnemonic & Definition & Unit \\
\hline $\begin{array}{l}\text { Metropolitan } \\
\begin{array}{l}\text { Performance } \\
\text { Urbanization }\end{array}\end{array}$ & Economic & $\mathrm{Y}$ & $\begin{array}{l}\text { Annual GDP in Guangzhou/Total } \\
\text { population } \\
\text { (non-agricultural population / total } \\
\text { population)*100 }\end{array}$ & $\begin{array}{l}\text { RMB/person } \\
\text { Total annual Consumption of }\end{array}$ \\
Water Consumption & $\mathrm{U}$ & Water/ Total population & cu.m/person \\
\hline
\end{tabular}


Table 1 lists all variables and their definitions used in the empirical analysis.

Table 2. Descriptive statistics

\begin{tabular}{cccc}
\hline VARIABLE & Y & W & U \\
\hline MEAN & 2.633973 & 0.009978 & 55.82714 \\
MEDIAN & 0.131641 & 0.009169 & 55.56978 \\
MAX & 19.83207 & 0.020340 & 67.96087 \\
MIN & 0.008424 & 0.000444 & 47.01945 \\
STD DEVIATION & 4.885201 & 0.007028 & 5.169785 \\
SKEWNESS & 2.135621 & 0.047695 & -0.022636 \\
KURTOSIS & 6.627690 & 1.486626 & 1.945452 \\
OBSERVATION & 66 & 66 & 66 \\
\hline
\end{tabular}

Table 2 lists summary statistics for every variable included in the sample. As shown by the information contained in Table 2, the sample data exhibit good variability. As would be expected for data from growing metropolitan economies, the skewness coefficients for the variables in Table 2 are noticeably greater than zero. The variables are also found to be strongly leptokurtic.

\subsection{Econometric Results}

In this section, the unit root tests with ADF approach, Perron's modified ADF with exogenous breakpoint and Zivot and Andrews's approach by break data endogenously are given before the Johansen Cointergration Test and ARDL Bounds Test Approach to Cointegration. At the end, the regressions for long run and short run using OLS and ARDL show the final empirical results about the relationship among urbanization, economic performance and water consumption.

\subsubsection{Unit Root Tests}

\section{(1) ADF Test}

Standard Granger causality tests have to be conducted on stationary time series. Following this line, we first test the unit roots of $\mathrm{Xt}$ to confirm the stationary properties of each variable. This is achieved by using the Augmented Dickey-Fuller test.ADF test is applied to detect the possible presence of unit roots in $\mathrm{Y}, \mathrm{W}$, and U. The null hypothesis of unit root can be rejected in favor of the alternative hypothesis of no unit root when the absolute value of ADF-test statistic is greater than the absolute value of critical value.

Table 3. ADF unit root test results

\begin{tabular}{llllllll}
\hline Levels & & \multicolumn{5}{c}{ First differences } \\
\hline Variables & $\begin{array}{l}\text { ADF-test } \\
\text { statistics }\end{array}$ & $\begin{array}{l}\text { Lag } \\
\text { length }\end{array}$ & $\begin{array}{l}\text { MacKinnon } \\
\text { critical values } \\
(5 \%)\end{array}$ & Variables & $\begin{array}{l}\text { ADF-test } \\
\text { statistics }\end{array}$ & $\begin{array}{l}\text { Lag } \\
\text { length }\end{array}$ & $\begin{array}{l}\text { MacKinnon } \\
\text { critical values }\end{array}$ \\
$\mathrm{Y}$ & 1.605244 & 8 & -3.490662 & $\Delta \mathrm{Y}$ & $1.647814^{*}$ & 9 & -1.612999 \\
$\mathrm{U}$ & -1.328671 & 0 & -3.480463 & $\Delta \mathrm{U}$ & $-6.708105^{* * *}$ & 0 & -4.107947 \\
$\mathrm{~W}$ & -1.938298 & 0 & -3.480463 & $\Delta \mathrm{W}$ & $-6.232793 * * *$ & 0 & -4.107947 \\
\hline
\end{tabular}

Note: * shows significance at $10 \%$ level; $* *$ shows significance at $5 \%$ level; $* * *$ shows significance at $1 \%$ level.

The results in table 3 show that all variables are non-stationary in their levels since the absolute values of test statistics for each variable are smaller than 5\% critical values. On the other hand, W,Y and $U$ are stationary processes in their first differences because the absolute values of test statistics for each variable are greater than MacKinnon critical values. Specifically, the absolute values of test statistics for $\mathrm{Y}$ are greater than $10 \%$ critical values, and the absolute values of test statistics for $\mathrm{U}$ and $\mathrm{W}$ are greater than $1 \%$ critical values. The leg length for each variable is chosen by the Eviews 9.0.

(2) Perron's modified ADF test with exogenous breakpoint

Perron's computation of modified Dickey-Fuller tests allows for levels and trends that differ across a single break date.

Table 4. Perron's modified ADF unit root test results

\begin{tabular}{llllllll}
\hline Variables & T-statistic & Break Data & $5 \%$ critical values & Variables & T-statistic & Break Data & 5\%critical values \\
\hline $\mathrm{Y}$ & -3.877079 & 2005 & -4.443649 & $\Delta \mathrm{Y}$ & $-5.033726^{* *}$ & 2003 & -4.443649 \\
$\mathrm{U}$ & -2.847252 & 1983 & -4.443649 & $\Delta \mathrm{U}$ & $-8.170638^{* *}$ & 2002 & -4.443649 \\
$\mathrm{~W}$ & -2.020571 & 1968 & -4.443649 & $\Delta \mathrm{W}$ & $-7.071947 * *$ & 2001 & -4.443649 \\
\hline
\end{tabular}

Note: **indicates significance at $5 \%$ level.

Table 4 reports that all variables are integrated of $\mathrm{I}(1)$ and thus stationary in first difference, comparing the absolute values of test statistics for each variable with the $5 \%$ critical values. The break date for each variable is chosen by the Eviews 9.0.

(3) Zivot and Andrews's test by break data endogenously 
The results of Zivot-Andrews are detailed in Table 5 which shows that non-stationary process is found in all series at level with intercept and trend but variables are found to be stationary at first difference.

Table 5. Zivot-Andrews's structural break trended unit root test results

\begin{tabular}{|c|c|c|c|c|c|c|c|}
\hline \multirow[t]{2}{*}{ Variables } & \multicolumn{3}{|l|}{ At Level } & \multirow[t]{2}{*}{ Variables } & \multicolumn{3}{|c|}{ At First Difference } \\
\hline & T-statistic & $\begin{array}{l}\text { Break } \\
\text { Data }\end{array}$ & $5 \%$ critical values & & T-statistic & Break Data & $5 \%$ critical values \\
\hline $\mathrm{Y}$ & -7.072308 & 1995 & -4.93 & $\Delta \mathrm{Y}$ & $-4.860837 * *$ & 1998 & -4.42 \\
\hline $\mathrm{U}$ & -2.699559 & 1984 & -4.93 & $\Delta \mathrm{U}$ & $-8.147100 * *$ & 2003 & -4.93 \\
\hline W & -3.202217 & 1985 & -4.93 & $\Delta \mathrm{W}$ & $-7.072308 * *$ & 1995 & -4.93 \\
\hline
\end{tabular}

Note: **indicates significance at $5 \%$ level.

Table 5 confirms that $\mathrm{W}, \mathrm{Y}$ and $\mathrm{U}$ are integrated at $\mathrm{I}(1)$. The break date for each variable is chosen by the Eviews 9.0.

\subsubsection{Cointegration Tests}

According to the unit root test results, integration of the variables is of the same order. We continued to test whether these variables are cointegrated over the sample period.

(1) Johansen Cointergration Test

Table 6 shows the results of the Johansen test.

Table 6. Johansen cointegration test results

\begin{tabular}{lccc}
\hline Hypothesized Number of Cointegrating equation & Trace Statistic & 5\%Critical Value & Eigenvalue \\
\hline None & 43.34525 & 42.91525 & 0.267003 \\
At most1 & 23.77660 & 25.87211 & 0.254798 \\
At most2 & 5.248292 & 12.51798 & 0.079931 \\
\hline
\end{tabular}

Note: $* *$ indicates significance at $5 \%$ level.

Because the trace statistic of none cointegrating equation and at less one cointegrating equation are greater than the $5 \%$ critical values, respectively, the test rejects the hypothesis of no cointegration, and indicates that there is at least one cointegrating equation at the $5 \%$ significance level, i.e. there may be a long-run relationship among $\mathrm{Y}, \mathrm{W}$ and $\mathrm{U}$ for Guangzhou.

(2) ARDL Bounds Test Approach to Cointegratio n

Armed with information about stationarity, we apply the ARDL bounds testing approach to cointegration.

Table 7. Bounds Test Results

\begin{tabular}{|c|c|c|c|c|}
\hline \multicolumn{5}{|c|}{ Bounds testing to cointegration } \\
\hline Estimated model & Lag length & F-statistic & $\begin{array}{l}5 \% \mathrm{C} \\
\mathrm{I}(0)\end{array}$ & $\mathrm{I}(1)$ \\
\hline $\mathrm{f}(\mathrm{Y} / \mathrm{U}, \mathrm{W})$ & $(4,0,0)$ & 2.023761 & 3.1 & 3.87 \\
\hline $\mathrm{f}(\mathrm{W} / \mathrm{Y}, \mathrm{U})$ & $(1,0,4)$ & $10.74961 * *$ & 3.1 & 3.87 \\
\hline $\mathrm{f}(\mathrm{U} / \mathrm{Y}, \mathrm{W})$ & $(2,3,0)$ & 2.024336 & 3.1 & 3.87 \\
\hline
\end{tabular}

Note: **indicates significance at $5 \%$ level.

The results of the bound test are given in Table 7. From these results, it is clear that there is only a long run relationship among the variables when $\mathrm{W}$ is the dependent variable, because the F-statistic is higher than the upper-bound critical value at the $5 \%$ level. This implies that the null hypothesis of no cointegration among the variables are rejected, when $\mathrm{W}$ is dependent variable. However, when $\mathrm{Y}$ and $\mathrm{U}$ are dependent variables, the null hypothesis of no cointegration is accepted.

\subsubsection{Results in the Long Run and Short Run using ARDL model}

After establishing cointegration among the series, we explore the long and short run relationship among Y and U on W in case of Guangzhou.

In terms of long run OLS model, the results reported in Table 8 show that $\mathrm{Y}$ and $\mathrm{U}$ both are positively related to $\mathrm{W}$ and it is statistically significant at one percent level. This implies that $\mathrm{Y}$ and $\mathrm{U}$ play vital role to drive up $\mathrm{W}$ in Guangzhou, which is consistent with hypothesis 1 and 2 .

Table 8 also reveals that the estimated error correction term of coefficient for ARDL short run regression is negative and significant at one percent level ensuring that the adjustment process from the short-run deviation to equilibrium is fast. The ARDL in long run and ARDL in short run estimated coefficients of $\mathrm{Y}_{\mathrm{t}-4}$ and $\Delta \mathrm{Y}_{\mathrm{t}-4}$ are positive and significant at ten percent level. This implies that there is a statistically significant, short-run lag over four periods with a positive impact of change of $\mathrm{Y}$ on the change of $\mathrm{W}$ in Guangzhou. That is to say, Y does not push up the W instantaneously, rather their impact appears four years later. The economic explanation of the result above is that there is a time tag 
effect of metropolitan economic performance on water consumption. So, there is a four years long process for the $\mathrm{Y}$ influencing W.

Additionally, the OLS and ARDL estimated coefficients of $\mathrm{W}_{\mathrm{t}-1}$ and $\Delta \mathrm{W}_{\mathrm{t}-1}$ are positive and significant at one percent level. This implies that there is a statistically significant short-run (lag one period) positive impact of change of $\mathrm{W}$ in last year on the change of $\mathrm{W}$. The economic meaning about the OLS and ARDL estimated coefficients of $\mathrm{W}_{\mathrm{t}-1}$ and $\Delta \mathrm{W}_{\mathrm{t}-1}$ is that the usage of water has been continuously increasing because of the effect of "path dependence" during the process of metropolitan economic development.

Table 8. Regressions for Long run and Short run using OLS and ARDL

\begin{tabular}{|c|c|c|c|c|c|}
\hline \multicolumn{3}{|c|}{ Long Run Regression } & \multicolumn{3}{|c|}{ Short Run Regression } \\
\hline \multicolumn{3}{|c|}{ OLS ( Dependent variable $=\mathrm{W}_{\mathrm{t}}$ ) } & \multicolumn{3}{|c|}{ OLS $\left(\right.$ Dependent variable $\left.=\Delta \mathrm{W}_{\mathrm{t}}\right)$} \\
\hline Independent & Coefficient & T-Statistics & Independent & Coefficient & T-Statistics \\
\hline Variables & & & Variables & & \\
\hline$Y_{t}$ & 0.000597 & $4.537936 * * *$ & $\Delta \mathrm{Y}_{\mathrm{t}}$ & $-4.70 \mathrm{E}-05$ & -0.925514 \\
\hline $\mathrm{U}_{\mathrm{t}}$ & 0.000663 & $5.333297 * * *$ & $\Delta \mathrm{U}_{\mathrm{t}}^{\mathrm{t}}$ & -0.000183 & -1.515664 \\
\hline \multirow{2}{*}{ Constant } & -0.028593 & $-4.219925 * * *$ & $\Delta \mathrm{ECT}_{\mathrm{t}-1}$ & 0.015791 & 1.082028 \\
\hline & & & Constant & $0.000362 * * *$ & 4.996196 \\
\hline \multicolumn{3}{|c|}{ ARDL ( Dependent variable =Wt) } & \multicolumn{3}{|c|}{ ARDL $($ Dependent variable $=\Delta \mathrm{Wt})$} \\
\hline $\mathrm{W}_{\mathrm{t}-1}$ & 1.032329 & $67.49180 * * *$ & $\Delta \mathrm{W}_{\mathrm{t}-1}$ & $1.256647 * * *$ & 4.117412 \\
\hline $\mathrm{Ut}$ & $2.98 \mathrm{E}-07$ & 0.018253 & $\Delta \mathrm{Ut}$ & $-3.02 \mathrm{E}-05$ & -0.610444 \\
\hline$Y_{t}$ & 0.000210 & 0.547253 & $\Delta \mathrm{Y}_{\mathrm{t}}$ & $2.30 \mathrm{E}-05$ & 0.061416 \\
\hline$Y_{t-1}$ & -0.001366 & $-2.140936 * *$ & $\Delta \mathrm{Y}_{\mathrm{t}-1}$ & $-0.000991 *$ & -1.771700 \\
\hline $\mathrm{Y}_{\mathrm{t}-2}$ & -0.000140 & -0.217858 & $\Delta \mathrm{Y}_{\mathrm{t}-2}$ & $-8.28 \mathrm{E}-05$ & -0.191726 \\
\hline$Y_{t-3}$ & -0.000406 & -0.531765 & $\Delta \mathrm{Y}_{\mathrm{t}-3}$ & 0.000129 & 0.228411 \\
\hline $\mathrm{Y}_{\mathrm{t}-4}$ & 0.002200 & $2.814121 * * *$ & $\Delta \mathrm{Y}_{\mathrm{t}-4}$ & $0.001323 *$ & 1.675756 \\
\hline \multirow[t]{2}{*}{ Constant } & 0.000171 & 0.200454 & $\mathrm{ECT}_{\mathrm{t}-1}$ & $-1.264877 * * *$ & -3.781713 \\
\hline & & & Constant & $-7.38 \mathrm{E}-05$ & -0.567226 \\
\hline
\end{tabular}

Note:* Shows significance at $10 \%$ level; $* *$ Shows significance at $5 \%$ level; $* * *$ Shows significance at $1 \%$ level.

\section{Conclusion}

To analyze the impact of urbanization and metropolitan economic performance on water consumption in Guangzhou City of China, econometric models are utilized with and without break date. The results of OLS and ARDL in long run show that metropolitan economic performance and urbanization both are positively related to water consumption and it is statistically significant at one percent level. This implies that metropolitan economic performance and urbanization play vital role to drive up water consumption in Guangzhou. So, the hypothesis 1 and 2 cannot be rejected. The empirical results also reveal that the OLS and ARDL estimated coefficients of $\mathrm{Y}_{\mathrm{t}-4}$ and $\Delta \mathrm{Y}_{\mathrm{t}-4}$ are positive and significant at ten percent level. This implies that metropolitan economic performance does not push up the water consumption instantaneously, rather their impact appears four years later. So, there is a four years long process for the metropolitan economic performance influencing water consumption.

\section{Acknowledgements}

The authors acknowledge financial support from the USDA research grant "Evaluating irrigation water quality regulation in fresh produce production: the case of Treasure Valley in Eastern Oregon and Southwest Idaho"[Grant No. 2016-67023-25068, Project No. WVA00909], Guangdong complementary fund of National Ten Thousand Outstanding Young Scholar Program “The Paradigm of Agricultural Deregulation”[2014SS075], the Project of Guangdong College Excellent Young Teacher Training Plan [Yq2014032], and the Key Project of National Natural Science Foundation in China [71333004].

\section{References}

Barbier, E. B. (2004). Water and Economic Growth, The Economic Record, 80(248), 1-16. https://doi.org/10.1111/j.1475-4932.2004.00121.x

Barron O. V., Barr, A. D., \& Donn, M. J. (2013). Effect of urbanisation on the water balance of a catchment with shallow groundwater. Journal of Hydrology, 485,162-176. https://doi.org/10.1016/j.jhydrol.2012.04.027

Carroll, C. D., Jody, O., \& David, N. W. (2000). Saving and Growth with Habit Formation. American Economic Review, 90(3), 341-355. https://doi.org/10.1257/aer.90.3.341

Cazcarro, I., Duarte, R., \& Sánchez-Chóliz, J. (2013). Economic growth and the evolution of water consumption in Spain: A structural decomposition analysis. Ecological Economics, (96), 51-61.

Chiang, A. C., \& Wainwright, K. (2004). Fundamental Methods of Mathematical Economics, New York, NY: McGraw-Hill, 4th ed. 
Engel, B. A., Ahiablame, L. M., \& Leroy, J. D. (2015). Modeling the impacts of urbanization on lake water level using L-THIA. Urban Climate, 14, 578-585. https://doi.org/10.1016/j.uclim.2015.10.001

Gleick, P. H. (2003). Water Use. Annual Review Environment and Resource, 28, 275-314. https://doi.org/10.1146/annurev.energy.28.040202.122849

Gober, P. 2010. Desert urbanization and the challenges of water sustainability. Current Opinion in Environmental Sustainability, 2, 144-150. https://doi.org/10.1016/j.cosust.2010.06.006

GSD. 2015. Guangzhou Statistical Yearbook. Guangzhou, CN: Guangzhou Municipal Bureau.

Haase, D. (2009), Effects of urbanisation on the water balance-A long-term trajectory, Environmental Impact Assessment Review, 29, 211-219. https://doi.org/10.1016/j.eiar.2009.01.002

Katz, D. (2015). Water use and economic growth: reconsidering the Environmental Kuznets Curve relationship, Journal of Cleaner Production, (88), 205-213.

Maheshwari, B., \& Bristow, K. L. (2016). Peri-urban water, agriculture and urbanization. Agricultural Water Management, 176, 263-265. https://doi.org/10.1016/j.agwat.2016.09.009

Ngoran, S. D., Xue, X. Z., \& Wesseh, P. K. Jr. (2016). Signatures of water resources consumption on sustainable economic growth in Sub-Saharan African countries. International Journal of Sustainable Built Environment, (5), $114-122$.

Srinivasan, V., Seto, K. C., Emerson, R., \& Gorelick, S, M. (2013). The impact of urbanization on water vulnerability: A coupled human-environment system approach for Chennai, India, Global Environmental Change, 23, 229-239. https://doi.org/10.1016/j.gloenvcha.2012.10.002

Wu Y. P., Liu, S. G., \& Chen, J. (2012). Urbanization eases water crisis in China, Environmental Development, 2, $142-$ 144.

Yan,T. T., Wang, J. X., \& Huang, J. K. (2015). Urbanization, agricultural water use, and regional and national crop production in China, Ecological Modelling, 318, 226-235. https://doi.org/10.1016/j.ecolmodel.2014.12.021

\section{Copyrights}

Copyright for this article is retained by the author(s), with first publication rights granted to the journal.

This is an open-access article distributed under the terms and conditions of the Creative Commons Attribution license which permits unrestricted use, distribution, and reproduction in any medium, provided the original work is properly cited. 